\title{
Development of an Aeroelastic Modeling Capability for Transient Nozzle Side Load Analysis
}

\author{
Ten-See Wang* \\ NASA Marshall Space Flight Center, Huntsville, Alabama, 35812 \\ Xiang Zhao ${ }^{\dagger}$, \\ Alabama A\&M University, Huntsville, Alabama, 35762 \\ Sijun Zhang \\ ESI CFD, Inc., Huntsville, Alabama, 35806 \\ and \\ Yen-Sen Chen ${ }^{\S}$ \\ Applied Research Laboratory, Hsinchu 30078, Taiwan, Republic of China
}

Lateral nozzle forces are known to cause severe structural damage to any new rocket engine in development. Currently there is no fully coupled computational tool to analyze this fluid/structure interaction process. The objective of this study was to develop a fully coupled aeroelastic modeling capability to describe the fluid/structure interaction process during the transient nozzle operations. The aeroelastic model composes of three components: the computational fluid dynamics component based on an unstructured-grid, pressure-based computational fluid dynamics formulation, the computational structural dynamics component developed in the framework of modal analysis, and the fluid-structural interface component. The developed aeroelastic model was applied to the transient nozzle startup process of the Space Shuttle Main Engine at sea level. The computed nozzle side loads and the axial nozzle wall pressure profiles from the aeroelastic nozzle are compared with those of the published rigid nozzle results, and the impact of the fluid/structure interaction on nozzle side loads is interrogated and presented.

\footnotetext{
* Aerospace Engineer, ER42, Fluid Dynamics Branch, Propulsion Structure, Thermal, and Fluids Analysis Division, Senior Member AIAA.

${ }^{\dagger}$ Associate Professor, Member AIAA.

* Senior Development Engineer, Member AIAA.

${ }^{\S}$ Senior Research Fellow, Senior Member AIAA.
} 


\section{Nomenclature}

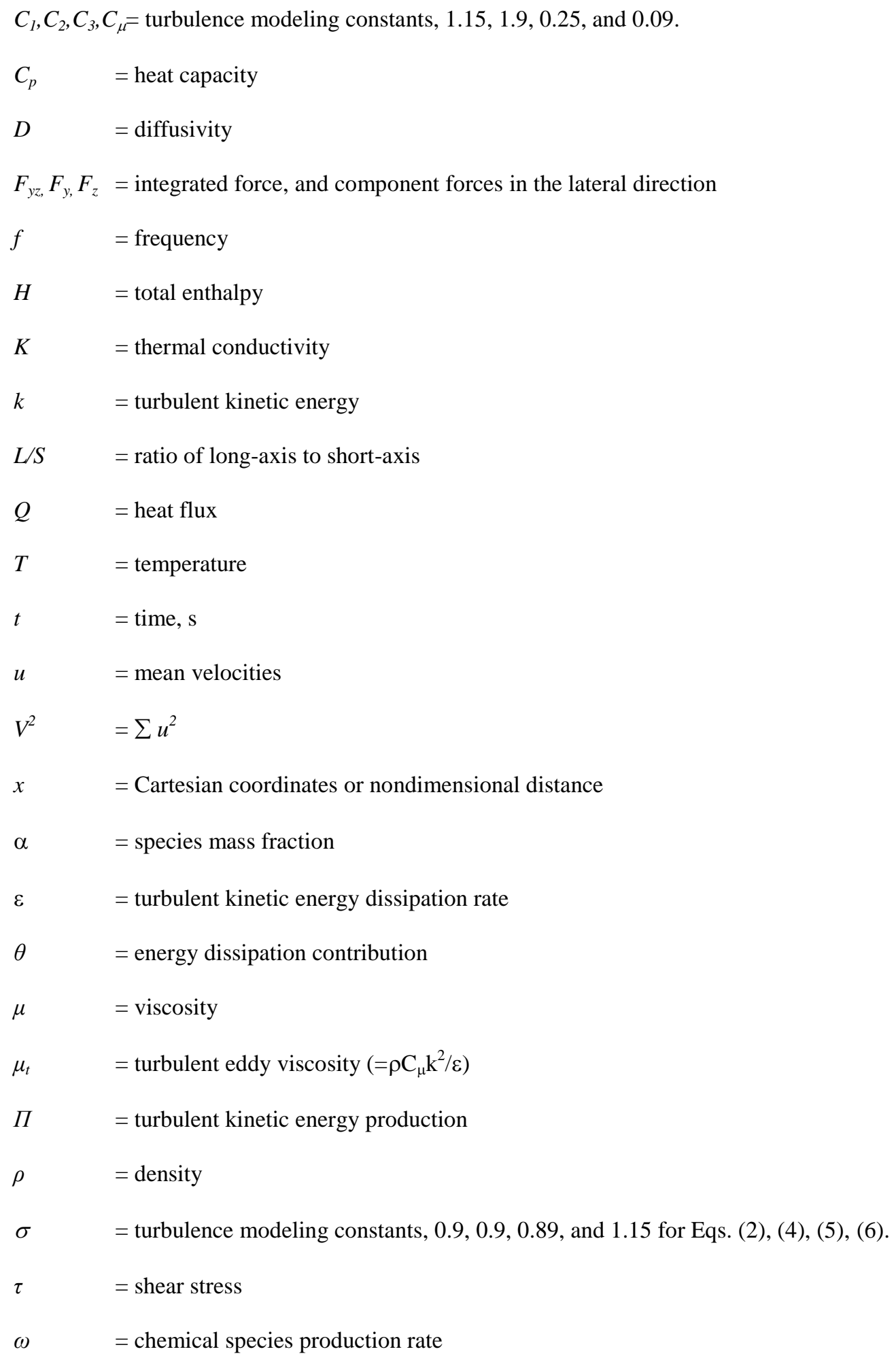

\section{Subscripts}




$$
\begin{array}{ll}
r & =\text { radiation } \\
t & =\text { turbulent flow }
\end{array}
$$

\section{Introduction}

Nozzle lateral forces during engine startup and shutdown transients, if not properly managed, are known to cause severe structural damage to the engine hardware for almost all liquid rocket engines during their initial development [1-4]. Transient nozzle side load is therefore considered a high risk item and a critical design issue. For that reason, many research efforts [5-19] have been devoted to understanding the side load physics and their impact on the magnitude of side loads. For regeneratively-cooled engines such as the Space Shuttle Main Engine (SSME), the peak side load generating physics have been identified as the $\lambda$ shock oscillation across the nozzle lip [7]. For filmcooled engines such as the Japanese LE-7A engine and the U.S. J-2X engine, the major side load generating physics have been associated with the jump of the separation line [3, 8]. Other side load physics such as the Free-Shock Separation (FSS)-to-Restricted-Shock Separation (RSS) transition have been mentioned as the critical physics for the European Vulcain engine [9].

In the aforementioned research efforts, computational fluid dynamics (CFD) have been demonstrated as a powerful analysis and design tool in computing and understanding the underlying transient side load physics inside a rigid nozzle. During an actual hot-firing of an engine, the nozzle wall or the structure of the nozzle, flexes or deforms in response to the lateral aerodynamic forces. The deformation of the nozzle wall simultaneously modifies the aerodynamic flowfield and the lateral forces, which in turn affects the nozzle wall deformation. This aeroelastic movement of the nozzle wall, which was not considered in the rigid nozzle modeling, is one of the important side load physics and needs to be considered.

The aeroelastic modeling of the transient nozzle side loads, requires the coupling of the CFD and computational structure dynamics (CSD) in order to describe the fluid-structure interactions (FSI). To the best of the authors' knowledge, there are only two recent exploratory papers [20, 21] that attempted to address this issue. Ref. 20 demonstrated the displacement of a two-dimensional, smooth nozzle wall of the J-2S engine at a fixed pressure ratio. Ref. 21 performed a quasi-static FSI simulation of a three-dimensional, smooth nozzle wall of the SSME. The computed elapse time, however, was only $0.02 \mathrm{~s}$ (out of a $5 \mathrm{~s}$ nominal startup transient) and the timing of the 
simulation was away from the two major side load physics, FSS-to-RSS transition and $\lambda$ shock oscillation across the nozzle lip.

In this effort and our first attempt on this subject, an aeroelastic model is being developed that composes of three components: the CFD component based on an unstructured-grid, pressure-based formulation, the CSD component developed in the framework of modal analysis, and the fluid-structural interface component. A three-dimensional simulation of the transient startup sequence of the SSME is being performed. The computed results with this aeroelastic model will be compared with those of the published SSME rigid nozzle effort [7].

\section{Computational Methodology}

\section{A. Computational Fluid Dynamics}

The computational fluid dynamics (CFD) methodology is based on a multi-dimensional, finite-volume, viscous, chemically reacting, unstructured grid, and pressure-based formulation. Time-varying transport equations of continuity, species continuity, momentum, total enthalpy, turbulent kinetic energy, and turbulent kinetic energy dissipation were solved using a time-marching sub-iteration scheme and are written as:

$$
\begin{aligned}
& \frac{\partial \rho}{\partial t}+\frac{\partial}{\partial x_{j}}\left(\rho u_{j}\right)=0 \\
& \frac{\partial \rho \alpha_{i}}{\partial t}+\frac{\partial}{\partial x_{j}}\left(\rho u_{j} \alpha_{i}\right)=\frac{\partial}{\partial x_{j}}\left[\left(\rho D+\frac{\mu_{t}}{\sigma_{\alpha}}\right) \frac{\partial \alpha_{i}}{\partial x_{j}}\right]+\omega_{i} \\
& \frac{\partial \rho u_{i}}{\partial t}+\frac{\partial}{\partial x_{j}}\left(\rho u_{j} u_{i}\right)=-\frac{\partial p}{\partial x_{i}}+\frac{\partial \tau_{i j}}{\partial x_{j}} \\
& \frac{\partial \rho H}{\partial t}+\frac{\partial}{\partial x_{j}}\left(\rho u_{j} H\right)=\frac{\partial p}{\partial t}+Q_{r}+\frac{\partial}{\partial x_{j}}\left(\left(\frac{K}{C_{p}}+\frac{\mu_{t}}{\sigma_{H}}\right) \nabla H\right)+\frac{\partial}{\partial x_{j}}\left(\left(\left(\mu+\mu_{t}\right)-\left(\frac{K}{C_{p}}+\frac{\mu_{t}}{\sigma_{H}}\right)\right) \nabla\left(V^{2} / 2\right)\right)+\theta \\
& \frac{\partial \rho k}{\partial t}+\frac{\partial}{\partial x_{j}}\left(\rho u_{j} k\right)=\frac{\partial}{\partial x_{j}}\left[\left(\mu+\frac{\mu_{t}}{\sigma_{k}}\right) \frac{\partial k}{\partial x_{j}}\right]+\rho(\Pi-\varepsilon) \\
& \frac{\partial \rho \varepsilon}{\partial t}+\frac{\partial}{\partial x_{j}}\left(\rho u_{j} \varepsilon\right)=\frac{\partial}{\partial x_{j}}\left[\left(\mu+\frac{\mu_{t}}{\sigma_{\varepsilon}}\right) \frac{\partial \varepsilon}{\partial x_{j}}\right]+\rho \frac{\varepsilon}{k}\left(C_{1} \Pi-C_{2} \varepsilon+C_{3} \Pi^{2} / \varepsilon\right)
\end{aligned}
$$

A predictor and corrector solution algorithm was employed to provide coupling of the governing equations. A second-order central-difference scheme was employed to discretize the diffusion fluxes and source terms. For the convective terms, a second-order upwind total variation diminishing difference scheme was used. To enhance the 
temporal accuracy, a second-order backward difference scheme was employed to discretize the temporal terms. Point-implicit method was used to solve the chemical species source terms. Sub-iterations within a time step were used for driving the system of second-order time-accurate equations to convergence. Details of the numerical algorithm can be found in Ref's [22-25].

An extended k- $\varepsilon$ turbulence model [26] was used to describe the turbulence. A modified wall function approach was employed to provide wall boundary layer solutions that are less sensitive to the near-wall grid spacing. Consequently, the model has combined the advantages of both the integrated-to-the-wall approach and the conventional law-of-the-wall approach by incorporating a complete velocity profile and a universal temperature profile [27]. A 7-species, 9-reaction detailed mechanism [27] was used to describe the finite-rate, hydrogen/oxygen afterburning combustion kinetics. The seven species are $\mathrm{H}_{2}, \mathrm{O}_{2}, \mathrm{H}_{2} \mathrm{O}, \mathrm{O}, \mathrm{H}, \mathrm{OH}$, and $\mathrm{N}_{2}$. The thermodynamic properties of the individual species are functions of temperature. The multiphysics pertinent to this study have been anchored in earlier efforts, e.g., SSME axial force and wall heat transfer [22], SSME startup side load and dominant shock breathing frequency [7], J-2X startup and shutdown side loads for a nozzlette configuration [8], nozzle film cooling applications [28], and conjugate heat transfer [29].

\section{B. Computational Structural Dynamics}

The structural dynamics response due to fluid flow actions has been analyzed using direct finiteelement analysis. The aeroelastic equations of motion of the solid bodies are given by

$$
[M]\{\ddot{Y}\}+[C]\{\dot{Y}\}+[K]\{Y\}=\{F\}
$$

where $\{Y\}$ is the displacement vector, $[M]$ is the mass matrix, $[C]$ is the damping matrix, $[K]$ is the stiffness matrix, and $\{F\}$ is the force vector due to the aerodynamic loads and shear stresses.

The motion Equation (7) of the structure can be solved using modal approach. On the basis of modal decomposition of the structure motion with the eigenvector of the vibration problem, the displacement, velocity and acceleration can be transformed to the generalized displacement, velocity and acceleration using a transformation matrix, which can expressed as the following: 


$$
\{Y\}=[\Phi]\{Z\} ;\{\dot{Y}\}=[\Phi]\{\dot{Z}\},\{\ddot{Y}\}=[\Phi][\ddot{Z}\}
$$

Here $[\Phi]$ is the mode shape matrix containing the eigenvectors, orthonormalized with the mass matrix.

$\{Z\},\{\dot{Z}\}$, and $\{\ddot{Z}\}$ are the generalized displacement, velocity and acceleration vectors, respectively. The eigenvectors are orthogonal to both mass and stiffness matrixes and if Rayleigh damping is assumed, it is also orthogonal to the damping matrix. Pre-multiplying Equation (8) by $[\Phi]^{\mathrm{T}}$, we get

$$
\{\ddot{z}\}+[\Phi]^{T}[C][\Phi][\dot{z}\}+[\Phi]^{T}[K I \Phi]\{Z\}=[\Phi]^{T}\{F\}
$$

where

$$
\left.[\Phi]^{T}[M] \Phi\right]=1
$$

Equation (3) can be written as $n$ individual equations, one for each mode, as follows

$$
\left\{\begin{array}{l}
\ddot{z}_{i}+2 \xi_{i} \omega_{i} \dot{z}_{i}+\omega_{i}^{2} z_{i}=r_{i} \\
r=\Phi_{i}^{T}\{F\}
\end{array}\right\} \mathrm{i}=1,2, \ldots, \mathrm{n}
$$

Here $\omega_{\mathrm{i}}$ is the natural frequency for the ith mode $\xi_{\mathrm{i}}$ is the corresponding damping parameter for that mode. The solution to Equation (10) can be obtained for each mode using direct integration algorithm.

\section{Transient Startup Sequences}

Transient system-level simulation is a vital part of the computational methodology, because it provides the timehistories of the inflow properties entering the nozzle. Simply put, the ramp rates, or histories, of the inlet pressure, 
fluid temperature and species concentrations play an important role in determining the type of side load physics, magnitude and duration of the side loads during the transient operations. In other words, the time-varying inlet flow properties determine the residence times of the side load generating flow physics inside the nozzle.

The system-level simulation is based on a lumped, control-volume approach to model the rocket engine as a network of components and sub-components. This method of transient system-level modeling has been shown to be effective in simulating the low-frequency, transient physics associated with the operation of previous and existing rocket engines (SSME, RL-10, IPD, etc.) and therefore, is an important tool in the design and planning of sequencing the transient events of rocket engine operation. Figure 1 shows some of the inlet flow properties obtained from the system model: the time-varying inlet pressure, temperature, and equivalence ratio profiles. These time-varying inlet properties were used at the injector faceplate of the thrust chamber for the CFD computation. Two significant pressure rise events can be identified in the inlet pressure history of Fig. 1. The first one occurs at $1.5 \mathrm{~s}$ due to oxygen prime, while the second one occurs at about $2.4 \mathrm{~s}$, caused by the step opening of the oxygen valves in the pre-burners. The inlet temperature history shows a sharp jump at $1.5 \mathrm{~s}$, leveling off after $1.75 \mathrm{~s}$, jumps a little bit again at $2.4 \mathrm{~s}$, and increases linearly until around $3.1 \mathrm{~s}$ when it reaches the final temperature. The inlet equivalence ratio history shows that the thruster environment is fuel rich throughout the start-up transient, especially in the first $1.5 \mathrm{~s}$, setting up the potential for afterburning. That turns out to be the source of the combustion wave, because the pressure jump at $1.5 \mathrm{~s}$

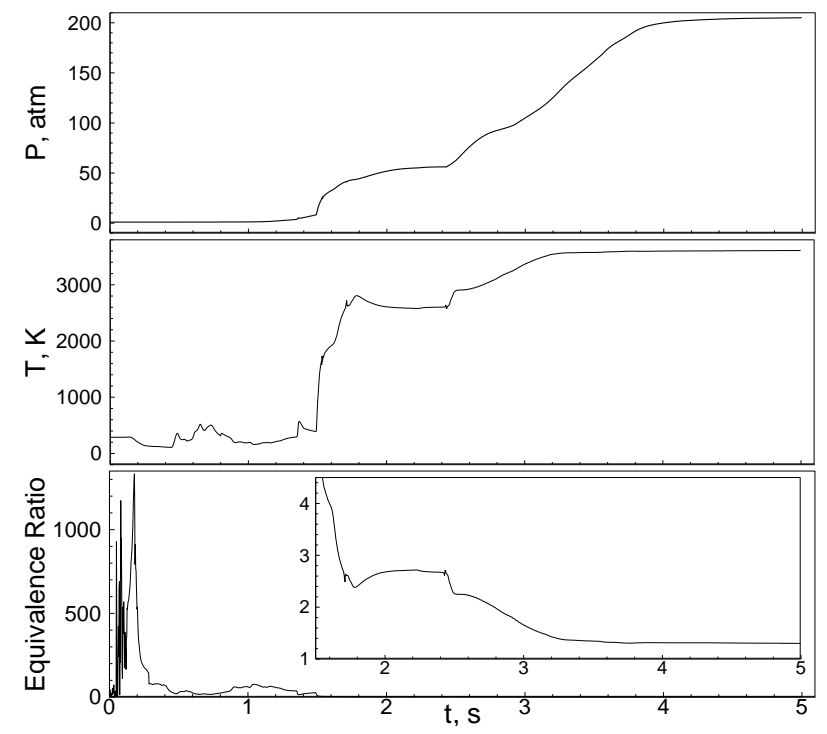

Fig. 1 Computed thruster chamber inlet properties during the start-up transient.

increases the reaction rate of afterburning, which

leads to the generation of the combustion wave. Afterburning plays an important part in the subsequent asymmetric flow physics such as the shock transitions and shock breathings across the nozzle lip. As mentioned in the beginning of this section, that the route or history between the starting and end points of any of the curves in Fig. 1 influences the side load physics intimately, any simplification on any part of the sequence may run the risk of missing or degradation of 
important side load physics. This SSME start transient process involves thermal-fluid physics phenomena and safetybased operating practices that are typical of a conventional LH2/LOX rocket engine.

\section{Computational Grid Generation}

This section will be completed when the final manuscript is due.

\section{Boundary and Inlet Conditions}

Since SSME is a first stage engine, fixed freestream boundary conditions were set corresponding to sea level. Time-varying inlet flow boundary conditions were used at the main combustion chamber (MCC) inlet. These inlet flow properties (obtained from the engine system model) were the time varying total pressure, temperature and propellant compositions. For engine startup computations, the thermal wall boundary condition was initially adiabatic. When the startup transient simulation reached $1.5 \mathrm{~s}$, the point where the MCC pressure started to ramp up, wall temperature profiles obtained from a separate steady-state calculation were imposed onto the MCC and

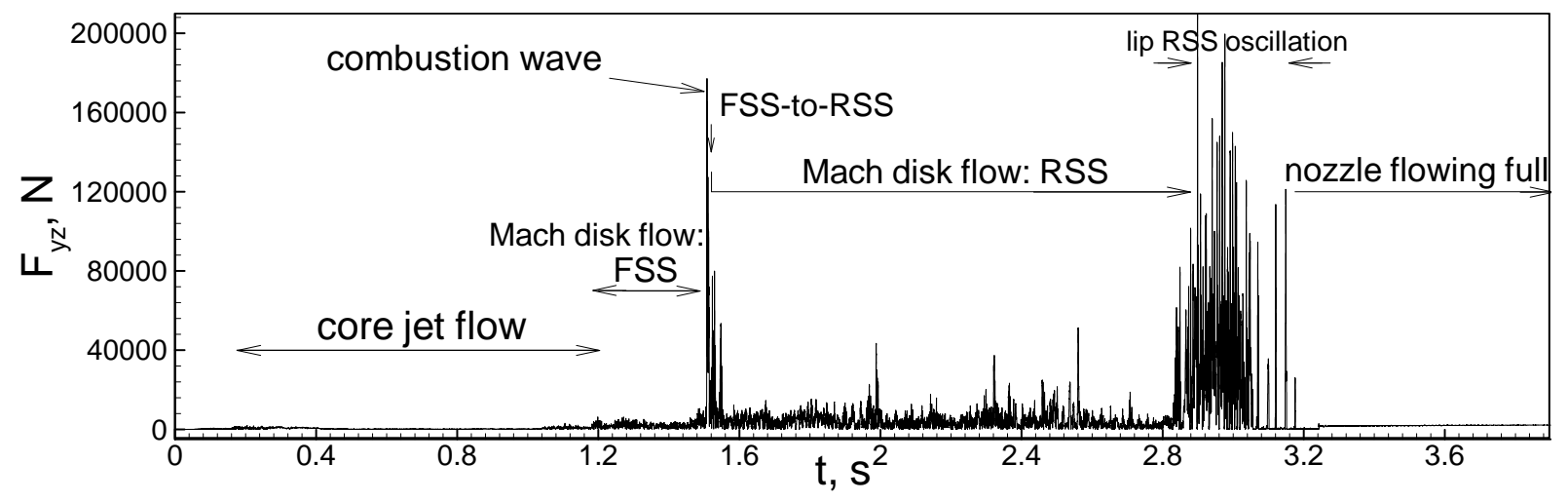

Fig. 2 Computed side forces for the rigid nozzle case.

regeneratively cooled nozzle wall.

\section{Preliminary Results and Discussion}

The computations were performed on a cluster machine using 10 to 15 processors. For these transient computations at sea level, the reaction rates of combustion are high and global time steps ranging from 1 to $10 \mu \mathrm{s}$ 
are expected to be used throughout the computations. These global time steps used correspond to CFL numbers ranging approximately from 0.1 to unity.

\section{The Rigid Nozzle Case}

Figure 2 shows the computed time-varying side loads and associated physics, simulating the SSME rigid nozzle hot-fired at sea level [7]. The side load physics captured included the combustion wave, FSS-to-RSS transition, and lip RSS oscillation (or breathing).
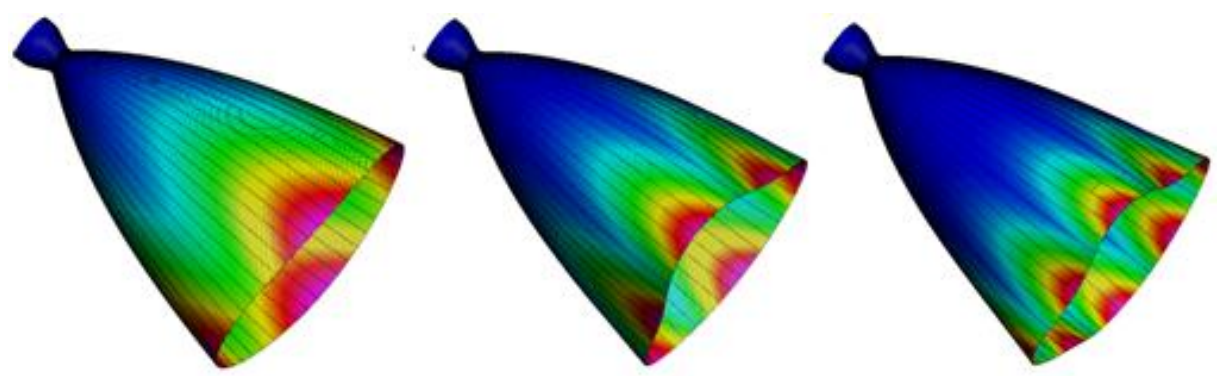

Fig. 3 Computed first three nodal diameter modes.

\section{The Aeroelastic Nozzle Case}

The aeroelastic-body computation is currently in progress. Figure 3 shows the deformation of the SSME nozzle due to the first-, second-, and third-nodal diameter modes. It is expected that the first-diameter mode, or the ovalization of the nozzle dominates the fluid-structure interaction during the transient startup process. At present moment, the modeling of the frequencies of the first three nodal diameter modes has been completed and a preliminary computation of the transient startup process is in progress.

\section{Conclusion}

The conclusion of the results will be ready when the final manuscript is due. 


\section{Acknowledgments}

Professor Zhao was partially supported by a Seed Grant from National Science Foundation and by a NASA 2012 Faculty Summer Fellowship. The authors wish to thank James Beck of Pratt-Whitney Rocketdyne for his interest in this task.

\section{References}

[1] Nave, L.H., and Coffey, G.A., "Sea Level Side Loads in High-Area-Ratio Rocket Engines,” AIAA Paper 73-1284, Nov. 1973.

[2] Cikanek, H.A., “Characteristics of Space Shuttle Main Engine Failures,” AIAA Paper 87-1939, June 1987.

[3] Watanabe, Y., Sakazume, N., and Tsuboi, M., "LE-7A Engine Nozzle Problems During the Transient Operations," AIAA Paper 2002-3841, July 2002.

[4] Shi, J., "Rocket Engine Nozzle Side Load Transient Analysis methodology - A Practical Approach," AIAA Paper 2005 1860, April 2005.

[5] Hagemann, G., Terhardt, M., Frey, M., Reijasse, P., Onofri, M., Nasuti, F., and Ostlund, J., "Flow Separation and Side-Loads in Rocket Nozzles," $4^{\text {th }}$ International Symposium on Liquid Space Propulsion, March 12-15, 2000, DLR Lampoldshausen, pp. 119.

[6] Yonezawa, K., Yokota, K., Tsujimoto, K., Sakazume, N., and Watanabe, Y., “Three-Dimensional Unsteady Flow Simulation of Compressed Truncated Perfect nozzles,” AIAA Paper 2002-3991, July 2002.

[7] Wang, T.-S., “Transient Three-Dimensional Startup Side Load Analysis of a Regeneratively Cooled Nozzle,” Shock Waves An International Journal on Shock Waves, Detonations and Explosions. Vol. 19, Issue 3, 2009, pp. 251 264. DOI: 10.1007/s00193-009-0201-2.

[8] Wang, T.-S., and Guidos, M., "Transient Three-Dimensional Side Load Analysis of a Film-Cooled Nozzle,” Journal of Propulsion and Power, Vol. 25, No. 6, 2009, pp. 1272-1280, doi: 10.2514/1.41025.

[9] Wang, T.-S., Lin, J., Ruf, J., Guidos, M., and Cheng, G.C., "Effect of Coolant Flow Distribution on Transient Side Load of Film Cooled Nozzles," Journal of Propulsion and Power, Vol. 28, No. 5, September-October, 2012, pp. 1081-1090. doi:10.2514/1.B34397

[10] Ostland, J., "Supersonic Flow Separation with Application to Rocket Engine Nozzles," Doctoral Thesis, Royal Institute of Technology, Stockholm, Sweden, 2004. 
[11] Deck, S., "Delayed Detached Eddy Simulation of the End-Effect Regime and Side-Loads in an Overexpanded Nozzle Flow," Shock Waves - An International Journal on Shock Waves, Detonations and Explosions. Vol. 19, Issue 3, 2009, pp. 239 249. DOI: 10.1007/s00193-009-0199-5.

[12] Hadjada, A., and Onofri, M., "Nozzle Flow Separation," Shock Waves - An International Journal on Shock Waves, Detonations and Explosions. Vol. 19, Issue 3, 2009, pp. 163 169. DOI: 10.1007/s00193-009-0209-7.

[13] Tomita, T., Takahashi, M., Sasaki, M., Sakamoto, H., Takahashi, M., Tamura, H., "Experimental Evaluation of Side Loads in LE-7A Prototype Engine Nozzle," Shock Waves - An International Journal on Shock Waves, Detonations and Explosions. Vol. 19, Issue 3, 2009, pp. 213 228. DOI: 10.1007/s00193-009-0191-0.

[14] Nguyen, A.T., Deniau, H., Girard, S., and De Roquefort, T.A., "Unsteadiness of Flow Separation and End-Effects Regime in a Thrust-Optimized Contour Rocket Nozzle,” Flow, Turbulence and Combustion, Vol. 71, 2003, pp.161-181.

[15] Deck S., and Guillen, P., "Numerical Simulation of Side loads in an Ideal Truncated Nozzle," Journal of Propulsion and Power, Vol. 18, No. 2, 2002, pp. 261-269.

[16] Shimizu, T., Miyajima, H., and Kodera, M., "Numerical Study of Restricted Shock Separation on a Compressed Truncated Perfect Nozzle," AIAA Journal, Vol. 44, No. 3, 2006, pp. 576-584.

[17] Stark, R., and Genin, C., “Optimisation of a Rocker Nozzle Side Load Reduction Device,” AIAA Paper 2012-3970, July 2012.

[18] Reijasse, Ph., and Boccaletto, L., "Influence of Film Cooling on Nozzle Side loads,” AIAA Paper 2008-392, Jan. 2008.

[19] Wang, T.-S., Lin, J., Ruf, J., and Guidos, M., “Transient Three-Dimensional Side Load Analysis of Out-of-Round Film Cooled Nozzles," Journal of Propulsion and Power, Vol. 27, No. 4, July-August, 2011, pp. 899-907, doi: 10.2514/1.B34082.

[20] Zhang, S.J., Fuchiwaki, T., and Zhao, X., “Aeroelastic Coupling and Side Loads in Rocket Nozzles”, AIAA Paper 20084064, June 2008.

[21] Blades, E.L., Luke, E.A., and Ruf, J., "Fully Coupled Fluid-Structure Interaction Simulations of Rocket Engine Side Loads,” AIAA Paper 2012-3969, July 2012.

[22] Wang, T.-S., "Multidimensional Unstructured-Grid Liquid Rocket Engine Nozzle Performance and Heat Transfer Analysis," Journal of Propulsion and Power, Vol. 22, No. 1, January-February, 2006, pp. 78-84.

[23] Shang, H.M., and Chen, Y.-S., "Unstructured Adaptive Grid method for Reacting Flow Computation,” AIAA Paper 1997 3183, July 1997.

[24] Wang, T.-S., Chen, Y.-S., Liu, J., Myrabo, L.N., and Mead, F.B. Jr., “Advanced Performance Modeling of Experimental Laser Lightcraft,” Journal of Propulsion and Power, Vol. 18, No. 6, 2002, pp. 1129-1138. 
[25] Chang, G., Ito, Y., Ross, D., Chen. Y.-S., Zhang S., and Wang, T.-S., "Numerical Simulations of Single Flow Element in a Nuclear Thermal Thrust Chamber” AIAA Paper 2007-4143, June 2007.

[26] Chen, Y.-S., and Kim, S. W., “Computation of Turbulent Flows Using an Extended k- $\varepsilon$ Turbulence Closure Model,” NASA CR-179204, Oct. 1987.

[27] Wang, T.-S., Droege, A., D’Agostino, M., Lee, Y.-C., and Williams, R., “Asymmetric Base-Bleed Effect on X-33 Aerospike Plume Induced Base-Heating Environment," Journal of Propulsion and Power, Vol. 20, No. 3, 2004, pp. $385-393$.

[28] Chen, Y.-S., Cheng, G.C., and Farmer, R.C., "Reacting and Non-Reacting Flow Simulation for Film Cooling in 2-D Supersonic Flows,” AIAA Paper 92-3602, July 1992.

[29] Wang, T.-S., Canabal, F., Chen, Y.-S., and Cheng, G.C., "Multiphysics Computational Analysis of a Solid-Core Nuclear Thermal Engine Thrust Chamber," Journal of Propulsion and Power, Vol. 26, No. 3, May-June, 2010, pp. 407-414. 